\title{
Applications of the Axiomatic Method in Social Science: The Declaration of Independence, Einstein and Ethics, and Balance and Dissonance Attitude Theories
}

\author{
Sheldon G. Levy \\ Department of Psychology, Wayne State University, USA
}

Copyright@2017 by authors, all rights reserved. Authors agree that this article remains permanently open access under the terms of the Creative Commons Attribution License 4.0 International License

\begin{abstract}
The value of the axiomatic method in conjunction with Muncaster's PropCalc Workplace to analyze and increase the precision of social science theory is illustrated through applications that include political philosophy, ethical reasoning, and theories of attitude change. All of the examples were originally expressed through verbal statements. A formal logical analysis is applied to the US Declaration of Independence which provides a set of propositions upon which governments are based, Einstein's essay on the laws of science and the laws of ethics, and basic concepts of balance and dissonance theories of attitude change. In each case, symbolic representations of the verbal language are then subjected to analysis for consistency and redundancy among the propositions and sample conclusions from each model are presented. The Muncaster's PropCalc is a valuable aid in identifying the integrity and consequences of the models. The discussion includes an examination of the relationship between the models and their correspondence with reality.
\end{abstract}

Keywords Axiomatic Method, Muncaster's PropCalc Workplace, US Declaration of Independence, Einstein's Laws of Ethics, Balance and Dissonance Attitude Theories

\section{Introduction}

The history of the axiomatic approach since Euclid [1] has relied on verbally stated propositions and application of logical analysis. Examples other than Euclid include Spinoza [2], Hull [3], and Smedslund [4]. The development of symbolic representations has resulted in the precision associated with mathematical systems in both the expressions of the assumptions and in the proofs of theorems. Although formal logical systems contain assumptions, axioms, postulates or premises, these are frequently the foundation of a mathematical analysis. However, in much of social science, the theoretical formulations, as distinct from the data analysis, are expressed verbally and the examination of the integrity of the theory is not based on formal logic. An important requirement before a theory is tested is to demonstrate that it is based on a logically coherent set of principles, that is, they do not contain contradictions and constitute an efficient set, that is not redundant. Recourse to the axiomatic method imposes a necessary precision in conceptualization and provides the basis for formal analysis based on fundamental logical principles. The following major sections represent a variety of social science approaches. For each, a background to the verbal development is first presented and the principles of the formulation are presented before developing a formal model that includes definitions and axioms. The propositions are stated based on four fundamental relationships--and, or, not and implies. The model is examined for its integrity (lack of contradictions) and redundancy. In each case, illustrative conclusions derived from the premises are briefly presented. The four analyses include the US Declaration of Independence [5, 6], the brief essay by Einstein on the laws of ethics [7], and the development in psychology of balance and dissonance theories of attitudes [8,9,10,11]. In all of the formal analyses presented the relationships--and, or, not, and implies--are symbolized by $\wedge, \mathrm{V},-$, and $\Rightarrow$, respectively.

\section{The Declaration of Independence ${ }^{1}$}

\subsection{Background}

The principles embodied in the US Declaration of Independence developed over a long period of history and with variation were present in many ancient societies. Fundamental to these was a judgment of fairness. However, whatever biological basis there is for restraints of one member of a species interacting with others, norms of the

1 Levy $[12,13]$ has presented analyses of the Declaration. 
social group greatly influence the judgment of fairness. Within English history, a significant event was the signing of the Magna Carta in 1215 [14]. This document contained some fundamental rights for those who were below royalty, although the principles did not always apply to the common citizen. They included (article number is in parens): (1) the English church will be free, (19 and 21) trials in the local area and, for earls and barons, trials by peers, (39), freedom to free-men unless trial by jury, and (41 and 42) freedom to travel from and return to the country. By the end of the next century John Wycliffe (Flory, [15]) argued a position later advocated by the Puritans that political obligations of the people were functional. By the mid $16^{\text {th }}$ century Ponet [16] argued that political authority was granted by the people and they, therefore, had the right to disobey when authority acted unjustly. (See also Goodman [17]).

The extent to which the framers of the Declaration of Independence intended to develop a political philosophy based on an axiomatic approach is unclear. The judgment that the attempt was deliberated appears to be based on a translation of Euclid that included the concept of self-evident propositions as a characteristic of axioms [18]. However, current translations labeled the axioms as "common notions"[1]. There were also postulates that were a part of the set of assumptions but not quite as fundamental. The language of the second paragraph of the Declaration of Independence does lend itself to analysis as an axiomatic system. The next section first develops the definitions and axioms as verbal statements and then expresses them in symbolic form. Based on the Muncaster PropCalc [19], the integrity of the developed set is examined as well as a sample of deductions derived by the Muncaster applet. The Muncaster PropCalc provides a computerized system for quickly analyzing some fundamental attributes of as set of premises. The symbolic form of the statements must first be converted to a form that is analyzable by the PropCalc. The ability to determine whether there are contradictions in a model as well as redundancies requires minimal time. In addition, a set of conclusions derived from the assumptions may be quickly obtained. As a result, the axiomatic approach to social science theory becomes far more feasible.

\subsection{The Declaration's “Self-evident” Paragraph}

"We hold these truths to be self-evident, that all men are created equal, that they are endowed by their Creator with certain unalienable Rights, that among these are Life, Liberty, and the pursuit of Happiness-That to secure these rights, Governments are instituted among Men, deriving their just powers from the consent of the governed,-That whenever any Form of Government becomes destructive of these ends, it is the Right of the People to alter or to abolish it, and to institute new Government, laying its foundation on such principles and organizing its powers in such form, as to them shall seem most likely to effect their Safety and Happiness.

\subsection{Analysis}

\subsubsection{Principles}

The statement from the Declaration is first separated into the verbal propositions and then analyzed by the set of definitions and premises that follow.

1. All men are created equal.

2. They are endowed with the unalienable rights of life liberty and the pursuit of happiness.

3. Governments are instituted to attain these benefits.

4. Governments derive their just power from the consent of the governed.

5. The citizens have the right to replace governments that are destructive of these ends.

Table 1 presents the model for the Declaration. It includes the symbols and their definitions and the symbolic representation of the propositions and their verbal translation.

Table 1. Formal model of the Declaration of Independence

\begin{tabular}{|c|c|}
\hline Symbols & Definitions \\
\hline $\begin{array}{l}\text { G } \\
\text { GR } \\
\text { GE } \\
\text { Gv } \\
\text { cnG } \\
\text { nGv }\end{array}$ & $\begin{array}{l}\text { The governed } \\
\text { The fundamental rights of the governed } \\
\text { The governed are equal in rights. } \\
\text { A legitimate government } \\
\text { The consent of the governed } \\
\text { The right of the governed to form a new government }\end{array}$ \\
\hline Proposition & Verbal description \\
\hline $\mathrm{Gv} \Rightarrow(\mathrm{cnG} \wedge \mathrm{GR})$ & $\begin{array}{l}\text { A legitimate government implies that it has both the consent of the governed and seeks to secure their } \\
\text { rights. }\end{array}$ \\
\hline $\mathrm{Gv} \Rightarrow \mathrm{GE}$ & A legitimate government implies that the governed have equal rights. \\
\hline$(-\mathrm{cnG} \mathbf{V}-\mathrm{GR}) \Rightarrow \mathrm{nGv}$ & $\begin{array}{l}\text { If there is either the lack of consent of the governed. or the government does not at least attempt to secure } \\
\text { their rights, the governed have the right to form a new government. }\end{array}$ \\
\hline$-\mathrm{GE} \Rightarrow \mathrm{nGv}$ & $\begin{array}{l}\text { If the governed do not have equal rights then they have the right to disband the government and form a } \\
\text { new one. }\end{array}$ \\
\hline
\end{tabular}




\subsubsection{Evaluation of the Model}

No redundancies were obtained among the propositions and there were no contradictions. The obtained conclusions were variations of the original propositions. Examples included:

- $\quad$ The lack of the consent of the governed implies that the governed have the right to form a new government.

- If the governed are not accorded their rights, the governed have a right to form a new government.

\section{Einstein, the Laws of Science and the Laws of Ethics [7]}

\subsection{Introduction}

In a short essay, Einstein [7] presents, in words only, a logical analysis of ethical reasoning. He suggested that although ethics involved the norms of should (values, good and evil) and these were beyond the scope of science, laws of ethics could be formulated and structured in a manner that was similar to that of science. His example was of lying. Based on human experience he argued that there were logical reasons why lying was wrong. Unlike axioms in pure mathematics, axioms in ethics were: “...derived from our inborn tendencies to avoid pain and annihilation, and from the accumulated emotional reaction of individuals in the behavior of their neighbors."

"Lying destroys confidence in the statements of other people. Without such confidence social co-operation is made impossible, or at least more difficult. Such co-operation, however, is essential, in order to make human life possible and tolerable. This means that the rule "'thou shalt not lie"' has been traced back to the demands: "'Human life shall be preserved"' and "pain and suffering shall be lessened as much as possible'.”

The analysis follows the pattern of that for the Declaration of Independence.

\subsection{Analysis}

\subsubsection{Principles}

1. Lying destroys confidence in the statements of other people.

2. Without such confidence social cooperation is made difficult or impossible.

3. Social cooperation is necessary to make human life possible and tolerable.

Table 2 presents the model for Einstein's statement.
Table 2. Formal model of Einstein's laws of ethics

\begin{tabular}{|c|c|}
\hline Symbols & Definitions \\
\hline P & Pain, suffering, threat to life \\
L & $\begin{array}{c}\text { Lying } \\
\text { Confidence } \\
\text { C }\end{array}$ \\
SC & Social Cooperation \\
\hline Proposition & Verbal description \\
\hline L $\Rightarrow-C$ & Lying implies a lack of confidence. \\
$-\mathrm{C} \Rightarrow-$ SC & A lack of confidence makes social cooperation \\
& impossible \\
$-\mathrm{SC} \Rightarrow$ P & $\begin{array}{c}\text { A Lack of social cooperation results in life that is } \\
\text { intolerable }\end{array}$ \\
\hline
\end{tabular}

\subsubsection{Evaluation of the Model}

There were no redundancies or contradictions among the axioms Examples of conclusions:

- A lack of confidence implies human suffering.

- $\quad$ Lying implies human suffering.

The importance of the formal development is examined further in the summary and discussion section.

\section{Balance Theory ${ }^{2}$}

\subsection{Introduction}

Explaining the conditions under which individuals are motivated to change attitudes and/or relationships is a basic goal in social psychology. Balance theory attempted to approach this problem by examining a simple social system, one in which there were only three elements, at least one of which was a person $[8,9,11]$. The system was from the perspective of one of its members and might be viewed differently by another member of the system. However, although perspectives might differ, the basic elements of the system remained the same. Not only was the social world limited but the conditions that existed in that world were also very restricted. There was a relationship between each pair of the elements. The relationship was either positive or negative and it was symmetric. The strength of all relationships was the same or unit strength. Given this seemingly simple world, there were assumptions about the set of relationships under which there would be stability (balance). Stability meant that there was no motivation for change. An unstable system was predicted to motivate activity to establish stability. Since the system could be described by three relationships, activity to achieve stability required a change in at least one of the relationships. Balance was assumed to occur when there was a positive relationship between two elements and the

2 A symbolic logic application to balance theory is in Abelson and Rosenberg, [20]. Their analysis is mathematically far more complex and includes additional concepts and relationships. 
relationships from each of those elements to the third were either both positive or both negative. Otherwise, there was imbalance.

\subsubsection{The verbal Propositions}

1. There are three elements.

2. At least one element is a person.

3. There is a relationship between each pair of elements.

4. A relationship is either positive or negative.

5. All relationships are symmetric.

6. All relationships have unit strength.

7. A balanced system is one in which there is no motivation to change at relationship.

8. A system that is not balanced is one in which there is a motivation to change at least one relationship.

9. Asystem is balanced if there is a positive relationship between two elements and the other relationships are the same, either positive or negative. All other combinations represent a system that is imbalanced.

Table 3 presents the model for balance theory.

Table 3. Formal model for balance theory

\begin{tabular}{|c|c|}
\hline Symbols & Definitions \\
\hline Pi, Pj, Pk & $\begin{array}{c}\text { P represents a positive relationships } \\
\text { and }- \text { P, a negative. } \\
\text { MCR } \\
\text {-MCR is the lack of motivation.. }\end{array}$ \\
\hline Propositions & Verbal description \\
\hline$(\mathrm{Pi} \wedge \mathrm{Pj} \wedge \mathrm{Pk}) \Rightarrow-\mathrm{MCR}$ & $\begin{array}{c}\text { If all three relationships are positive, } \\
\text { there is no motivation to change a } \\
\text { relationship. }\end{array}$ \\
$(\mathrm{Pi} \wedge \mathrm{Pj} \wedge-\mathrm{Pk}) \Rightarrow \mathrm{MCR}$ & $\begin{array}{c}\text { If two relationships are positive and } \\
\text { one is negative, there is motivation to } \\
\text { change at least one relationship. } \\
\text { If one relationship is positive and two } \\
\text { are negative, there is no motivation to } \\
\text { change a relationship. }\end{array}$ \\
$(\mathrm{Pi} \wedge-\mathrm{Pj} \wedge-\mathrm{Pk}) \Rightarrow-\mathrm{MCR}$ & $\begin{array}{c}\text { If all relationships are negative, there } \\
\text { is a motivatin to change at least one } \\
\text { relationship. }\end{array}$ \\
\hline
\end{tabular}

Since the social system may be described by three relationships, the relationships may be defined as the basic elements.

\subsubsection{Evaluation of the Model}

No redundancies or contradictions were found. Following are examples of conclusions.

A motivation to change a relationship implies that not all relationships are positive.

A lack of motivation to change a relationship implies that not all relationships are negative.

\section{Dissonance Theory}

\subsection{Introduction}

Dissonance theory $[10,11]$ may be viewed as a variation of balance theory but the variation has profound implications. ${ }^{3}$ Dissonance examines a three element system in which the individual has cognitions that are related to each other. It is the relationship between the cognitions that is the essential factor. While it is reasonable to posit that in the typical case there is a positive relationship between the individual and that person's cognitions, motivational conditions depend on the relationship between the cognitions. Dissonance theory posits that the relationship is positive if the two cognitions are logically related, that is one implies the other. For example, the belief that smoking is bad for one's health implies behavior, and the cognition of that behavior, that the individual is a non-smoker. The two are negatively related if one implies the other but the contradiction exists; the individual is aware of being a smoker. The positive and negative relationships are a translation of the language of the original dissonance theory. The effect of consonance and dissonance are similar to those of balance and imbalance. When there is dissonance, there is motivation to change a relationship, in this case, between the cognitions. Dissonance theory further posits that this occurs through adjusting the weaker cognition. Where one cognition is of a belief, smoking is bad for heath, and the other is of a behavior, awareness of being a smoker, the assumption is that it is easier to alter the belief than to deny the awareness of one's actions and the prediction would be that the belief would change in the attempt to achieve logical consistency..

Dissonance theory also incorporates the concept of external justification--the greater the external justification, the smaller the contradiction between two illogically related cognitions. There are several approaches to incorporating external justification. One is to evaluate the alternate logic that is frequently activated by the external justification. The individual then creates a system that is logical under these circumstances. For example, if a person has a self-awareness of honesty and lies to another person, there should be dissonance.. However, if the person also has an awareness of being practical and is offered a large sum of money to engage in a harmless practical joke, it would be illogical for the person to not accept the offer.

Another means of analysis would be to admit the external justification as a fourth element and analyze the system based on the Cartwright and Harary's application of digraph theory [22]. In addition to accommodating systems of more than three elements, the analysis does not require that all relationships be present. The present analysis adds external justification as another concept in the model and includes

3 Insko, Worchel, Folger, and Kutkus [21] have provided one interpretation of dissonance theory based on balance. The analysis in this presentation is a more direct approach to the relationship. 
additional postulates that state its implications.

Dissonance theory itself contains an assumption that is necessary to deduce the logical relationship. That is the assumption about the individual. Smoking is a contradiction of the belief that smoking is bad for one's health if the individual is not a risk-taker who believes in challenging the odds. A large number of studies have focused on differences in individual risk-taking preferences, for example, Kahneman and Tversky [23], Ross [24] and Loewenstein, Weber, Hsee, and Welch [25].

Similarly, lying is inconsistent with one's beliefs, if the person does not believe in gaining an advantage over others through deception. It is not necessary to be a psychopathic liar for an individual to express deception for a variety of reasons. (Truth about deception, for a discussion of lying [26]).

\subsection{Verbal Propositions}

1. The set of three elements includes an individual and two cognitions.

2. Dissonance occurs when one cognition implies another but a contradictory cognition exists.

3. Dissonance induces a motivation to reduce or eliminate the contradiction.

4. The reduction in the contradiction occurs by a change in the weaker of the two.

5. When there is dissonance, external justification reduces the strength of the contradiction.

Table 4. Formal model of dissonance theory

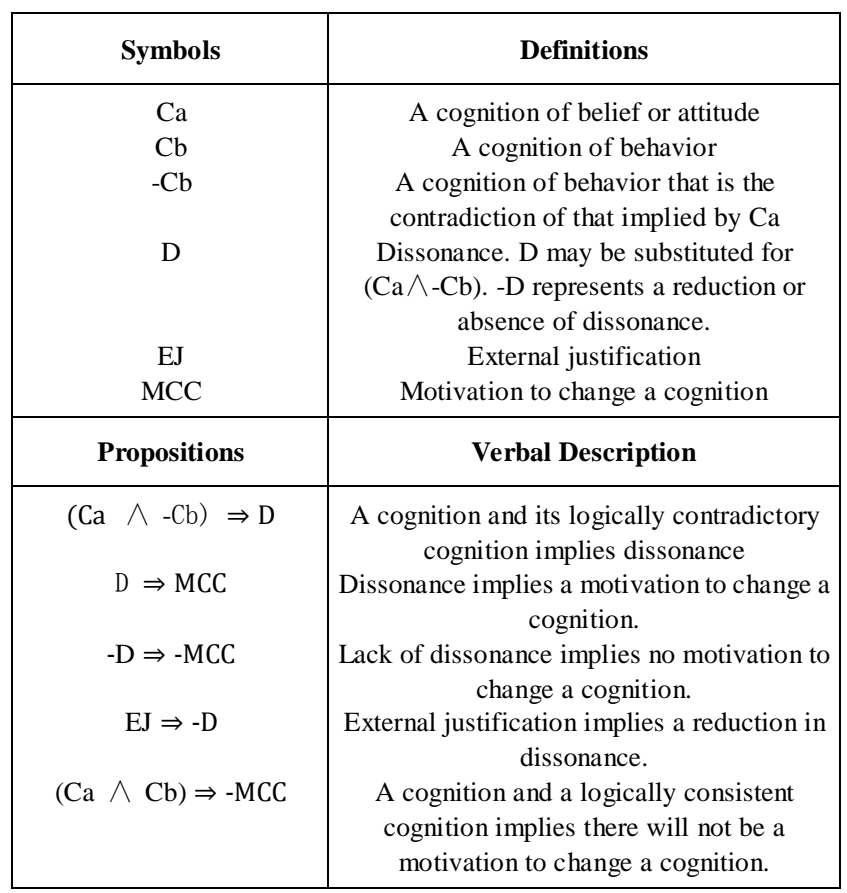

Although the analysis follows the balance paradigm, the set of symbols has been altered since the relationship of the individual to the cognition is assumed to be positive. The third relationship may be either positive or negative. If negative as a result of a contradiction, dissonance is hypothesized to motivate a change. Table 4 presents the model for dissonance theory. For purposes of clarity, the formulation that the cognitions of two beliefs may also be contradictory and therefore lead to dissonance has not been included in the model. However, the conflict between two beliefs may have large implications for both cognitive and behavioral change (See for example, Smelser [27]).

\subsection{Evaluation of the Model}

The five axioms were non-redundant and were internally consistent. Among the conclusions implied by the axioms were the following:

- An attitude and the presence of a logically contradictory cognition implies motivation to change a cognition.

- Dissonance implies a lack of external justification.

- External justification implies that there is not both an attitude and a cognition of behavior that is a contradiction of that implied by the attitude.

- Motivation to change a cognition implies a lack of external justification.

\section{Summary and Discussion}

A series of verbally expressed theories has been reformulated in symbolic terms and the resulting set of assumptions has been tested for contradictions and redundancy. Examples of conclusions from the formal model have been presented. The advantage of the symbolic approach is the advantage of any mathematical formulation of a set of ideas, an increase in precision in both statement and the logic by which conclusions are derived. The utility of the approach was enhanced by the disparate nature of the formulations - political philosophy, ethics, and two theories of attitude change. As with all theories, the ideas must be tested against reality. In science, this frequently means through prediction.

The substance of the propositions of each of the theories may be questioned. The unalienable rights of the Declaration may not be self-evident. This is a minor limitation. The statement, with loss of eloquence, might have been: We hold these principles to be a fundamental basis for human society. Those who disagreed with that might have formulated a different philosophy in which a basic proposition might have been:--the king holds his position by divine right (Filmer [28]). Different conclusions derive from different assumptions.

Although Spinoza [2] provided an elaborate set of postulates in his effort to develop a comprehensive ethical system, the purpose of the analysis in this paper was not to evaluate the Spinoza model. Instead, Einstein's essay was selected because it is a very direct set of verbal principles that relates reasoning in ethics to that of science. It therefore, represents an amenable example of the diversity of 
applications of the axiomatic method with basic symbolic representation. Einstein's assumptions might also be questioned (with trepidation, but he formulated them as an illustration, not a formal theory). A core principle was that lying was wrong because it destroyed confidence which was necessary for cooperation which in turn was necessary for achieving decent human life. However, lying only destroys confidence (the liar loses credibility) if the lying is discovered. History is replete with examples of lies which were believed and resulted in greater confidence in the lying leader, often with destruction to the believers themselves. Further, it is possible that sometimes a lie represents justification for already desired behavior. Dissonance theory might accommodate such a paradox. The facts contradict the hatred but the desire for the hatred is so strong that a distortion of the facts, even if known, may be accepted. The premise of the individual in this instance might be stated: If the denigration of the target is intense, then any negative characteristic attributed to the target is a justification for action even if the attribution is believed to be false. In this instance, the process, termed psycho-logic, is based on the reasoning of the individual. Since the reasoning of psycho-logic is based on the perceptions and thoughts of the individual, the reasoning frequently involves formal logical errors. This has led to the labeling of such reasoning as irrational. While this may be an accurate characterization of much psycho-logic, it does not mean that there do not exist premises of a formal logical system that may account for the conclusions that appear "irrational.” In the present example, the possible premise that a negative attribute about a highly denigrated group is an attribute of the members of the group even when the negative characteristic is believed to be false, could lead to a formal conclusion, given some additional assumptions, that hostile action is justified. ${ }^{4}$

Balance theory assumes that it is the relationships that define stability or instability. But, as Rodrigues has shown, other factors such as symmetry and positivity may lead to stability even when the system is not balanced [33]. Finally, dissonance theory has some problems in precision. One key element is the assumption of the missing middle which may not always be the same for all individuals. As discussed in the illustration of the smoker, there are risk-takers and risk-avoiders and a uniform assumption about individuals may be unwarranted. These limitations of the theoretical formulations do not detract from the axiomatic method for expressing the theory. The axioms are not an empirical test of the theory.

\subsection{Limitations of the Analysis}

\subsubsection{Lack of Generality of Models}

Euclid's axioms were of a domain, the plane. Spinoza's

4 Psychological research and theory have provided numerous presentations of the effects of inner state on what is actually perceived. For example, Bruner and Goodman, [29], Bruner and Postman [30], McClelland [31] and Pious [32] discuss the concept of perceptual hypotheses. was of ethics, and the Declaration was of political philosophy. From a mathematical point of view, axioms are frequently expressed as generalities, such as a set of points and a set of relationships. However, such a set is almost always incomplete since it does not accommodate many variations in the domain [Wilder, 34]. As a result, axioms are frequently not all inclusive---Newton's axioms were of motion, Hull's of human behavior, and Smedslund's of health behavior. Whether someone eventually will be capable of combining a set of systems into a field theory is not clear. At this point, the value of the approach is of sufficient merit to warrant further development.

\subsubsection{Triviality of the Conclusions}

The derivations from the models that were presented were not of great significance. The verbal statements of the theories might be judged as easily leading to the conclusions without any symbolic representation. In fact, in all of these examples, the language was specifically designed to provide a logical basis. However, again referring to ancient history, Euclid's theorems probably would not have emerged as conclusions in the PropCalc analysis. The development of theorems requires additional insights. However, the formal system provides the basis for establishing that the theorems are in fact logically derivable from the premises.

The corollary of triviality is the absence of relevant substance. For example, the conclusions derived in the analysis of the Declaration do not include the Bill of Rights. In both the Declaration and in Einstein's essay a number of variations were subsumed under a single concept. Thus, the people, the citizens, the public, and the governed were all defined in the Declaration model as the governed. Einstein also included a number of variations in arguing for the motivation of individuals to achieve a "tolerable" existence. Tolerable included more than the avoidance of annihilation, but also a reduction in pain and suffering.

These points may be reinforced by developing a proposition from the Bill of Rights and incorporating it as a premise in the original model. The addition of the missing desired conclusion allows a determination of redundancy. If the added statement is redundant, it was derivable from the original premises even though it did not appear among the conclusions. Otherwise, it represents an expansion of the model.

The first amendment of the US constitution prohibits congress from making any law that establishes or infringes on religious freedom, that interferes with free speech or the freedom of the press, or that prohibits peaceable assembly by the citizens to petition for a redress of grievances. In the original model, GR was the symbol for the basic rights of the people. Therefore, a principle might be that the governed have a right to a free press and that censorship interferes with this right. $\mathbf{C}$ represents censorship and $\mathbf{F P}$ represents a free press. GR implies FP and $\mathbf{C}$ implies -FP. These premises are added to the original model:

$$
\mathrm{Gv} \Rightarrow(\mathrm{cnG} \wedge \mathrm{GR})
$$




$$
\begin{gathered}
\mathrm{Gv} \Rightarrow \mathrm{GE} \\
(-\mathrm{cnGV}-\mathrm{GR}) \Rightarrow \mathrm{nGv} \\
-\mathrm{GE} \Rightarrow \mathrm{nGV} \\
\mathrm{GR} \Rightarrow \mathrm{FP} \\
\mathrm{FP} \Rightarrow-\mathrm{C}
\end{gathered}
$$

The analysis identified no redundancies in the expanded model. Therefore, the additional specificity is required to achieve the statements in the Bill of Rights. That results from the fact that the concept of fundamental rights in the Declaration does not specify those rights that are to be included. As identified by subsequent amendments to the Constitution, new fundamental rights were established as a result of further insights and beliefs about those rights that are fundamental. The UN declaration of fundamental human rights [35] extends beyond the US constitution's bill of rights and presently a debate in the US is the question of whether health care is a fundamental right. Whether or not additional axioms are required depends upon the list of rights that are incorporated into the concept of "fundamental rights". If free speech were a fundamental right, then censorship would be an infringement and a government that did not seek to safeguard the people against censorship would no longer be legitimate.

\subsection{Conclusions}

Most philosophies are verbal Social science theory is primarily verbal as is language. Legal proceedings are verbal. It is clear that reasoning, sometimes at a very intricate level, may occur through verbal argument. The advantage of formal analysis, with a further refinement attained through symbolic representation, is that rules of logic are explicitly applied to derive conclusions. Psychology has attained accomplishments, with the study of attitudes a notable example, without, for the most part, symbolic representation. An argument might also be entered that discoveries were also achieved in physics before the application of calculus. However, the great advances occurred after a mathematical language was added to verbal reasoning. There is no reason to believe that such changes could not also be achieved in social science. The rather elementary analyses presented in this paper are merely an attempt to suggest how the incorporation of symbolic argument might aid the achievements of social science.

\section{REFERENCES}

[1] Euclid (circa 300 B.C.E/2008.). Elements. Fitzpatrick, R., translation and edited. The elements of Euclid's geometry. ISBN 978-0-6151-7984-1. Retrieved from: http://www.google.com/url?sa=t\&rct=j\&q=\&esrc=s\&source= web\&cd=1\&ved=0ahUKEwiL2omA37LRAhVM6oMKHSi5
DQkQFggcMAA\&url=http\%3A\%2F\%2Ffarside.ph.utexas.ed u\%2FBooks\%2FEuclid\%2FElements.pdf\&usg=AFQjCNFek 8wsmce-Szo2IA8hidHr1vopmw

[2] Spinoza, B. (1675) The ethics. Translated from the Latin by R. H. M. Elwes. Posting Date: May 28, 2009 [Ebook \#3800] project Gutenberg e

[3] Hull, C. L. (1943). Principles of Behavior. New York: Appleton-Century-Croft

[4] Smedslund, G. (2000). A Pragmatic basis for judging models and theories in health psychology: The axiomatic method. Journal of Health Psychology, 5(2) 133-149.

[5] Declaration of Independence (2017/1776) The Final Text of the Declaration of Independence July 4 1776, from American History from Revolution to Reconstruction and Beyond. At: URL

http://www.let.rug.nl/usa/documents/1776-1785/the-final-text -of-the-declaration-of-independence-july-4-1776.php

[6] Declaration of Independence (2017/1776]. The Declaration of Independence: Full text - US History.org URL: www.ushistory.org/declaration/document/

[7] Einstein, A. (1953/1950) The laws of science and the lasws of ethics. In Feigel, Herbert and Brodbeck, May (ed.) Readings in the philosophy of science. Pp. 778-779 New York; Appleton-Century-Crofts

[8] Heider, F. (1946) Attitude and cognitive organization. Journal of Psychology, 21, 107-112.

[9] Newcomb, T. M (1953). An approach to the study of communicative acts. Psychological Review, 60, 393-404.

[10] Festinger, L. and Carlsmith, J. M.. Cognitive consequences of forced compliance. Journal of Abnormal and Social Psychology, 58, 203-210.

[11] Kiesler, C.A., Collins, B.F. and Miller, N. (1969). Attitude change: a critical analysis of theoretical approaches. New York: Wiley and Sons.

[12] Levy, S. G. (2015). The Role of Logic in Testing and Developing Psychological Theory: The Value of Some Formality, Division 24, APA, Society for Theoretical and Philosophical Psychology. March 5, Salt Lake City.

[13] Levy, S. G. (2017). The Role of the Axiomatic Method in Psychology. Michigan Academy of Sciences Arts and Letters, March 10, Western Michigan University, Kalamazoo.

[14] Magna Carta (1215) at URL: www.bsswebsite.me.uk/History/MagnaCarta/magnacarta-121 5.htm

[15] Flory, L. (2016) Wycliffe and Heresy. Electronic journals hosted by university libraries. URL: journals.wichita.edu/index.php/ff/article/download/147/154

[16] Ponet, J. (1556/2017] A Short Treatise on Political Power, and of the true obedience which subjects our to kings and other civil governors, with an Exhortation to all true and natural English men. ) Edited version (Patrick S. Poole0 downloaded from URL: http://www.constitution.org/cmt/ponet/polpower.htm

[17] Goodman, C. (1558/2017). How Superior Powers Ought To 
Be Obeyed By Their Subjects: And Wherein They May Lawfully By God's Word Be Disobeyed And Resisted. Edited version (Patrick S. Poole downloaded from URL: http://www.constitution.org/cmt/goodman/obeyed.htm

[18] Simon, R. (1806/2007) "The elements of Euclid, viz. the first six books, together with the eleventh and twelfth. Digitized in 2007. URL:

https://archive.org/stream/elementsofeuclid00eucluoft/elemen tsofeuclid00eucluoft_djvu.txt

[19] Muncaster. R. G., (2017).

http://www.math.uiuc.edu/ muncast/Applets/Applets34E72A /index.html

[20] Abelson, R. P. and Rosenberg, M. J. (1958.) Symbolic psycho-logic: A model of attitudinal cognition. Behavioral science, 3, p. 1-13.

[21] Insko, C. A.; Worchel, S.; Folger, R.; Kutkus, A. (1975) A balance theory interpretation of dissonance. Psychological Review, 82(3), 169-183.

[22] Cartwright, D. and Harary, F. (1956). Structural balance: a generalization of Heider's theory, Psychological Review, 63: 277-293.

[23] Kahneman, D. and Tversky, A.. (1979). "Prospect Theory: An Analysis of Decision Under Risk," Econometrica 47, 263-291.

[24] Ross, S. A. (1981) Some Stronger Measures of Risk Aversion in the Small and the Large with Applications. Econometrica 49(3) pp. 621-638.

[25] Loewenstein GF, Weber EU, Hsee CK, and Welch N. (2001) Risk as felling. Psychological Bulletin, 127(2) PP. 267-286.
[26] Truth about deception (2017). What is the difference between a sociopath, a compulsive, a pathological, a chronic, and a habitual Liar? At URL:

https://www.truthaboutdeception.com/lying-and-deception/co nfronting-a-partner/compulsive-lying/

[27] Smelser, N. J. (1962). Theory of collective behavior. New York: The Free Press.

[28] Filmer, R. (1680). Patriarch; on the natural power of kings. London: Robert Christwell.

[29] Brimer. J. S. and Goodman, C. C. (1947). On value and need as organizing needs in perception. The journal of abnormal and social psychology, 41 (1), 33-44.

[30] Bruner, J.S. and Postman, L. (1946), Symbolic value as an organizing factor in perception. Journal of Social Psychology, 27, 203-208

[31] McClelland, D. C. (1967). The achieving society. New York: Free Press.

[32] Pious, S. (1998) Selective Perception. Ch. 1 in The psychology of judgment and decision-making. New York: McGraw-Hill

[33] Rodrigues, A. (1965) On the differential effects of some parameters of balance. The Journal of Psychology, Interdisciplinary and Applied, 61 (2), 241-250. Published online: 04 Nov 2012.

[34] Wilder, R. L. (1965). Introduction to the foundations of mathematics. New York: John Wiley and Sons

[35] Universal declaration of human rights (1948/2017). Dounload URL:

www.un.org/en/udhrbook/pdf/udhr_booklet_en_web.pdf 